\title{
Opportunity Costs of Sub-Optimal Diversification
}

\author{
James A. Yunker \\ Professor of Economics, Western Illinois University \\ Macomb, Illinois 61455, USA \\ E-mail: JA-Yunker@wiu.edu \\ Alla A. Melkumian \\ Associate Professor of Economics, Western Illinois University \\ Macomb, Illinois 61455, USA \\ E-mail: AA-Melkumian@wiu.edu
}

Received: April 27, 2012

Accepted: May 10, 2012

Online Published: June 6, 2012

doi:10.5430/afr.v1n2p25

URL: http://dx.doi.org/10.5430/afr.v1n2p25

\begin{abstract}
The practical relevance of the extensive theoretical literature on optimal diversification has been brought into question by a wide variety of research that suggests individual investors utilize investment principles that are distinctly sub-optimal relative to theoretical principles. If these indications are indeed legitimate, this might be owing to the irrationality of investors, or to imperfections in the theoretical models. The present research suggests a third possibility: that the numerical payoff to optimal diversification is relatively minor. On the basis of a numerically implemented and empirically supported model of optimal diversification developed by Yunker and Melkumian (2010), the present research finds that the numerical opportunity costs (welfare losses) from sub-optimal diversification are quite minor even for substantial departures from the optimal levels of the decision variables. The suggestion from the research is therefore that individual investors tend to "satisfice" rather than "maximize" or "optimize" in making their diversification decisions.
\end{abstract}

Journal of Economic Literature Classifications: G11 (Portfolio Choice, Investment Decisions)

Keywords: Diversification, Portfolio choice, Investment analysis, Stock ownership

\section{Introduction}

As an implementation of the proverbial adage against putting all one's eggs in one basket, it has become axiomatic in both the popular and professional literature on investments that the individual investor should significantly diversify his/her portfolio in order to reduce exposure to risk. But what kind of diversification, and how much diversification, is required in order that the investor attain a reasonable approximation to the maximum benefit level?

Following the seminal work of Markowitz $(1952,1959)$, a rich theoretical literature has developed on optimal diversification: Samuelson (1967), Brennan (1975), Goldman (1979), Morgan (1995), Phillips, Cathcart and Teale (1996), Kocherlakota (1996), King and Leape (1998), Giliberto, Hamelink, Hoesli and MacGregor (1999), Cheng and Liang (2000), Dynkin, Hyman and Konstantinovsky (2002), Gomes and Livdan (2004), Polkovnichenko (2005), McClatchey and Vandenhul (2005), Frederik (2006), Bera and Park (2008), Goetzmann and Kumar (2008), Polbennikov, Desclee and Hyman (2010), Mainik and Ruschendorf (2010), Ghosh (2010). However, the relevance of the extensive theoretical literature to the investment behavior of real-world individual investors is somewhat questionable. A number of investigators have found what seem to be irrational investment strategies among investors relative to theoretically optimal strategies.

Benartzi and Thaler (2001) observed that investors' portfolio decisions are often influenced by restricted availability of investment options. Duchin and Levy (2009) determined that investors holding small portfolios (fewer assets) follow the naïve investment strategy while investors holding large portfolios (more assets) tend to follow the mean-variance investment strategy. Kaustia and Knupfer (2008) noted that personal investment experience (defined as "reinforced learning") significantly impacts investors' actions and in many cases outweighs theoretically optimal investment strategies. De Wit (1998) found empirical indications that, assuming asset returns are identically and 
independently distributed, the naïve portfolio strategy is best in terms of risk reduction and assets returns expectations. Poterba and Samwick (2003) found that portfolio decisions are often based on taxability of available investment assets and the investor's own income. Alessie, Hochguertel and van Soest (2004) determined that adjustment costs (rebalancing a portfolio) make it optimal to invest in one type of asset, in most cases stocks only. Mitton and Vorkink (2007) concluded that under-diversification brings a higher degree of skewness to the investor's portfolio, which increases the probability of a very high pay-off. Polkovnichenko (2005) argued that almost all investors' portfolios are preference-based and are therefore under-diversified in theoretical terms. Phillips, Cathcart and Teale (2007) pointed out that Australian self-managed pension plans perform much worse than the S\&P 500 stock market composite index (an equally-weighted portfolio) or the ASX 300 index (an Australian equivalent of S\&P 500), due to an even lower degree of diversification. Elton, Gruber and Busse (2004) argue that investors' irrational actions support the existence and growth of inferior assets which in turn makes arbitrage possible.

Additional research contributions indicating that individual investors variously trade too much, hold under-diversified portfolios, maintain unprofitable positions for too long, expect to be overcompensated for idiosyncratic risk, invest too heavily in their own companies, assume too much or too little risk, and so on, include the following: Blume and Friend (1975), Ferris, Haugen and Makhija (1988), Brainard (1991), Kelly (1995), Green and Rydqvest (1997), Odean (1998), Carroll (2000), Barber and Odean (2000), Grinblatt and Keloharju (2001), Hirshleifer and Luo (2001), Huberman (2001), Cohen, Gompers and Vuolteenaho (2002), Vissing-Jorgensen and Attanasio (2003), Mitton and Vorkink (2007), Guiso and Paiella (2008), Calvet, Campbell and Sodini (2009), Basu, Oomen and Stremme (2010).

Do these and similar contributions suggest that many if not most individual investors are in fact irrational in their portfolio management? This seems questionable in light of the fundamental assumption in the discipline of economics of human rationality. In the matter at hand here, perhaps the theoretical models of optimal portfolio diversification do not adequately incorporate such complicating factors as transaction costs, asymmetric information among investors, costs of information acquisition, differing investment horizons of investors, differing availability of investment options, personal investment experience (reinforced learning), different tax treatments of available investment assets, and preference-based choice of assets. Still another possibility, examined in this research, is that the opportunity costs of sub-optimal diversification are likely to be numerically small. In other words, if the investor has already achieved a modest level of diversification, it could be that the gains from further diversification are relatively minor.

To investigate this possibility, we utilize the optimal diversification model developed by Yunker and Melkumian (2010). This model permits a mathematically explicit solution for the optimal level of diversification in terms of proportion of total portfolio value allocated to stocks, and the number of individual stocks in the stock portfolio. Moreover, Yunker and Melkumian provide significant statistical support for the model based on empirical data from the well-known FRB Survey of Consumer Finances. This research investigates the numerical losses from progressively greater divergences from the optimal level of diversification according to this model. It is found that these losses are numerically small over a wide range of parameter values. The larger implication of this finding is that one reason for apparently irrational investment behavior among individual investors may simply be that the payoff to seeking the maximum benefit is relatively small.

\section{The Homogeneous Securities Model}

Following Yunker and Melkumian (2010), we utilize a "homogeneous securities" model of portfolio choice, as follows:

Let the capital wealth of an individual be denoted assets $a$. The proportion of $a$ held in stocks is $\rho$, and the proportion held in bonds is $1-\rho$. The wealth constraint is:

$$
s+b=\rho a+(1-\rho) a=a
$$

where $s$ and $b$ denote the holdings of stocks and bonds respectively. To simplify the analysis the variance of bond returns is set to zero. The rate of return on bonds, $r_{b}$, is then the risk-free rate of interest.

Using the capital asset pricing model, the rate of return on stock issue $i$, denoted $r_{s, i}$, is:

$$
r_{s, i}=r_{b}+\beta_{i}\left(r_{m}-r_{b}\right)+\varepsilon_{s, i}
$$

where $\beta_{i}$ is the beta coefficient of stock issue $i, r_{m}$ is the value-weighted market return, and $\varepsilon_{s, i}$ is the residual disturbance for stock issue $i$, with expected value zero and variance $\sigma_{s, i}^{2}$. Under the homogeneous securities 
assumption, $\beta_{i}=1$ for all securities, and the mean and variance of the residual disturbance $\varepsilon_{s, i}$ for each stock issue are the same: $\mathrm{E}\left(\varepsilon_{s, i}\right)=\mathrm{E}\left(\varepsilon_{s}\right)=0$ and $\sigma_{s, i}^{2}=\sigma_{s}^{2}$. Thus for all $i$, the random variable $r_{s, i}=r_{m}+\varepsilon_{s}$ has expected value $\bar{r}_{s}=\bar{r}_{m}$ and variance $\sigma_{m}^{2}+\sigma_{s}^{2}$. Since $s$ is a high return asset, we assume $\bar{r}_{s}>r_{b}$.

The first diversification decision variable of the capital owner is $\rho$, the proportion of total capital assets to be held in the form of stock issues. The capital owner then sub-divides the stock portfolio equally over $n$ different stocks. The number of stocks held is the second decision variable. For analytical purposes, it will be taken to be a continuous variable, although in practice, of course, it must be a discrete variable taking only integer values. The model specifies that an equal amount is held in each stock. This is not efficient according to most portfolio choice models, but it is apparently descriptive of real-world practices among many if not most investors, as indicated in contributions by De Wit (1998), Cheng and Liang (2000), Benartzi and Thaler (2001), Stevenson (2001), Windcliff and Boyle (2004), McCatchey and Vandenhul (2005), Melkumian and Melkumian (2009), and Duchin and Levy (2009). Also, this specification is consistent with the model assumption that all stocks are alike.

The cost of transacting in each security is assumed to be a fixed amount $c$. Then the rate of return on investment, net of the fixed costs of transacting, is:

$$
r=\sum_{i=1}^{n} r_{s, i} \frac{\rho}{n}+r_{b}(1-\rho)-n(c / a)\left(1+r_{b}\right)
$$

The expected value and variance of rate of return are:

$$
\begin{aligned}
& \mathrm{E}(r)=\bar{r}_{s} \rho+r_{b}(1-\rho)-n(c / a)\left(1+r_{b}\right) \\
& \mathrm{V}(r)=\rho^{2}\left(\sigma_{m}^{2}+\frac{\sigma_{s}^{2}}{n}\right)
\end{aligned}
$$

Using a conventional mean-variance formulation, the criterion function to be maximized is:

$$
L=\mathrm{E}(r)-\lambda \mathrm{V}(r)=\bar{r}_{s} \rho+r_{b}(1-\rho)-n(c / a)\left(1+r_{b}\right)-\lambda\left(\rho^{2}\left(\sigma_{m}^{2}+\left(\sigma_{s}^{2} / n\right)\right)\right)
$$

where $\lambda$ represents the marginal rate of transformation of risk for return. This parameter measures the investor's degree of risk aversion: the higher the $\lambda$ value, the more the investor is adverse to risk.

The $L$-maximizing values of $\rho$ and $n$ are shown by Yunker and Melkumian (2010) to be as follows:

$$
\begin{aligned}
& \rho^{*}=\frac{.5\left(\bar{r}_{s}-r_{b}\right)}{\lambda \sigma_{m}^{2}}-\frac{\sqrt{\sigma_{s}^{2}(c / a)\left(1+r_{b}\right)}}{\sigma_{m}^{2} \sqrt{\lambda}} \\
& n^{*}=\frac{.5 \sigma_{s}\left(\bar{r}_{s}-r_{b}\right)}{\sigma_{m}^{2} \sqrt{\lambda(c / a)\left(1+r_{b}\right)}}-\frac{\sigma_{s}^{2}}{\sigma_{m}^{2}}
\end{aligned}
$$

Since (7) and (8) are explicit formulae for optimal $\rho^{*}$ and $n^{*}$, the comparative statics effects of the parameters on optimal diversification may be ascertained directly by differentiation. For optimal $\rho^{*}$ : (1) $d \rho^{*} / d a>0$; (2)

$d \rho^{*} / d \bar{r}_{s}>0$; (3) $d \rho^{*} / d \sigma_{s}^{2}<0$ and $d \rho^{*} / d \sigma_{m}^{2}<0$; (4) $d \rho^{*} / d r_{b}<0$; (5) $d \rho^{*} / d \lambda<0$; and (6) $d \rho^{*} / d c<0$. These are intuitively expected results because, respectively: (1) higher investor wealth enables a higher level of diversification because the investor can afford higher transactions costs; (2) a higher expected rate of return on stocks makes them more attractive; (3) a higher variance on stock return makes stocks riskier and hence less attractive; (4) a higher rate of return on bonds makes stocks relatively less attractive; (5) a higher level of risk aversion on the part of the capital owner, as reflected in a larger value of $\lambda$, makes risky stocks less attractive; and (6) a higher transactions cost on stocks makes them less attractive. Because $\rho^{*}$ and $n^{*}$ are proportional to one another, the signs of the comparative statics derivatives for $n^{*}$ are the same as those for $\rho^{*}$.

Of the parameters determining optimal $\rho^{*}$ and $n^{*}$, only two are specific to the investor: capital assets $a$, and risk aversion $\lambda$. Of these two, $\lambda$ is unobservable but $a$ is observable. To test the model empirically, Yunker and Melkumian obtained a data set from the 2004 Survey of Consumer Finances containing 4,519 households. The three key variables in the data set are the proportion of total capital wealth held in the form of stock issues $(\rho)$, the number of individual stock issues held in the stock portfolio $(n)$, and the total capital wealth of the household $(a)$. Isolating the $a$ parameter, the respective relationships between $\rho^{*}$ and $a$, and $n^{*}$ and $a$, from (7) and (8), are as 
follows:

$$
\begin{aligned}
& \rho^{*}=\phi_{1}-\phi_{2} \frac{1}{\sqrt{a}} \text { where } \phi_{1}=\frac{.5\left(\bar{r}_{s}-r_{b}\right)}{\lambda \sigma_{m}^{2}} ; \phi_{2}=\frac{\sqrt{\sigma_{s}^{2} c\left(1+r_{b}\right)}}{\sigma_{m}^{2} \sqrt{\lambda}} \\
& n^{*}=\psi_{1} \sqrt{a}-\psi_{2} \text { where } \psi_{1}=\frac{.5 \sigma_{s}\left(\bar{r}_{s}-r_{b}\right)}{\sigma_{m}^{2} \sqrt{\lambda c\left(1+r_{b}\right)}} ; \psi_{2}=\frac{\sigma_{s}^{2}}{\sigma_{m}^{2}}
\end{aligned}
$$

where the $\phi$ and $\psi$ parameters are all positive. It is apparent that both $\rho^{*}$ and $n^{*}$ are concave increasing functions of total capital wealth $a$. Furthermore, whereas $n^{*}$ increases indefinitely with $a$, there is an asymptotic upper limit on $\rho^{*}$ at $\phi_{1}=.5\left(\bar{r}_{s}-r_{b}\right) / \lambda \sigma_{m}^{2}$.

To test the model, regression estimates were obtained of (9) and (10): observed $\rho$ was regressed on $1 / \sqrt{a}$, and observed $n$ was regressed on $\sqrt{a}$, for the entire data set, and for aggregated data sets of 100 observations and 25 observations respectively. The non-intuitive forms (9) and (10) were supported by the regressions. The key independent variables $1 / \sqrt{a}$ and $\sqrt{a}$ were significant at a high level of confidence, and the total explanatory power of the regression equations were quite high for the aggregated data sets owing to the suppression of random variation within brackets. For example, the $\rho$ regression equation had an R-squared of 0.80 for the 25 -bracket dataset and 0.69 for the 100 -bracket data, relative to 0.09 for the full dataset.

\section{Costs of Sub-Optimal Diversification}

Table 1 presents the effect on the model criterion variable $L$ of departures from the optimal values of $\rho$ and $n$, for parameter values: $\bar{r}_{s}=0.08 ; r_{b}=0.04 ; \sigma_{m}^{2}=0.025 ; \sigma_{s}^{2}=0.050 ; \lambda=1 ; c=5 ; a=250,000$. For these parameter values, the calculated optimal proportion of portfolio value devoted to stocks, and optimal number of stocks in the stock portfolio, are respectively $\rho^{*}=0.7592$ and $n^{*}=37.22$. For these values of the decision variables, the calculated maximum value of the criterion variable is $L^{*}=0.054410$.

The three parts of the table are in matrix form, with the result for optimal diversification in the center of a 7 by 7 array. Along the side of each matrix are sub-optimal values for proportion in stocks $\rho: 30$ percent below the optimum $(0.5314=0.7 \times 0.7592) ; 20$ percent below the optimum $(0.6074=0.8 \times 0.7592) ; 10$ percent below the optimum $(0.6833=0.9 \times 0.7592)$; at the optimum $(0.7592=1 \times 0.7592) ; 10$ percent above the optimum $(0.8351=1.1 \times$ $0.7592) ; 20$ percent above the optimum $(0.9110=1.2 \times 0.7592)$; and 30 percent above the optimum $(0.9870=1.3 \times$ $0.7592)$. Sub-optimal values for number of stocks $n$ are along the top: 30 percent below the optimum $\quad(26.06=0.7 \mathrm{x}$ $37.22) ; 20$ percent below the optimum $(29.78=0.8 * 37.22) ; 10$ percent below the optimum $(33.50=0.9 \times 37.22)$; at the optimum $(37.22=1 \times 37.22) ; 10$ percent above the optimum $(40.95=1.1 \times 37.22) ; 20$ percent above the optimum $(44.67=1.2 * 37.22)$; and 30 percent above the optimum $(48.39=1.3 \times 37.22)$.

The upper part A of Table 1 shows the value of the criterion variable $L$ for each combination of $\rho$ and $n$ values. As we move away from the maximum in any direction, the value of $L$ falls, but as can be seen, the $L$ value does not fall by a large amount. Figure 1 shows a surface plot of values of $L$ against combinations of $\rho$ and $n$ values. The 3-dimensional figure manifests a dome-shaped configuration with the apex of the dome over the optimal $\rho$ and $n$ values. The fact that there is not much variation in the $L$ value over the range of $\rho$ and $n$ values is apparent from the narrow range of $L$ values on the vertical axis.

The middle part $\mathrm{B}$ of the table shows the $L$ declines around the maximum value in percentage terms. For example, the lowest value of $L$ in upper part A of the table occurs for $\rho=0.9870$ (30 percent above the optimum $\rho$ value) and $n=26.6$ (30 percent below the optimum $n$ value). This $L$ value $(0.052715)$ represents a 3.115378 percent decline relative to the maximum $L$ value of $0.054410:(3.115378=100((0.054410-0.052715) / 0.544410)$. As can be seen, the percentage changes in the middle part B of Table 1 are all relatively low values, using the standard percentage range from 0 percent to 100 percent. But whether any specific percentage value may be deemed high or low might depend on the units of measure in an underlying relationship.

In order to evade the units of measure problem, economic measurements are often presented in elasticity terms: the percentage change in the dependent variable (e.g., quantity of a good demanded), divided by the percentage change in the independent variable (e.g., price of the good). To apply the elasticity concept to the percentage losses shown in the middle part $\mathrm{B}$ of Table 1, we take the mean percentage loss over all cases in which the two decision variables are both the same percentage below or above their optimal levels. The lower part $\mathrm{C}$ of Table 1 shows all cases in which 
this is true. For example, the first-row, first-column element (0.079452) is the computed elasticity when proportion $\rho$ is 30 percent below the optimum and number $n$ is 30 percent below the optimum. In this case the computed elasticity is $2.383559 \%$ divided by $30 \%=0.079452$. The first-row, seventh-column element $(0.092587)$ is the computed elasticity when proportion $\rho$ is 30 percent above the optimum and number $n$ is 30 percent below the optimum. In this case the computed elasticity is $2.777615 \%$ divided by $30 \%=0.092587$. And so it goes around the corners of the matrix. Double-headed arrows connect the relevant elasticity values. At the bottom of the table is shown the computation for 30 percent above and below optimal $\rho$ and $n$ values: $0.088834=(0.079452+0.092587+0.079452$ $+0.103846) / 4$. The same procedure is utilized for computing losses in elasticity terms for 20 percent departures from optimal values, and 10 percent departures from optimal values. These average loss elasticities are respectively 0.058897 and 0.029359 .

The three computed elasticities at the bottom of Table 1 ( 0.029359 for a 10 percent deviation away from the optimum, 0.058897 for a 20 percent deviation away from the optimum, and 0.088834 for a 30 percent deviation away from the optimum) are all quite small, representing less than one tenth of one percent. A similar computation was done for larger departures from the optimum: respectively 40 percent, 60 percent and 80 percent. The highest average loss in elasticity terms was observed for 80 percent departures from the optimal levels: 0.275116 . This is slightly over one fourth of one percent.

\section{Sensitivity Analysis}

Any results based on numerical computations may be questioned as to the generalizability of the qualitative implications. Perhaps the qualitative results are specific to whatever numerical parameter values have been utilized in the computations. To answer this question, it is customary to present results from alternative computations using different parameter values.

Table 2 shows the results from comparative statics computations for three model parameters: capital assets $a$ (upper part A), risk aversion $\lambda$ (middle part B), and transactions cost $c$ (lower part $\mathrm{C}$ ). For model parameters other than those being varied, the Table 1 values were utilized. For each of a range of values of a specific parameter below and above the Table 1 value, the optimal $\rho^{*}, n^{*}$ and $L^{*}$ values are shown, along with the average $L$ loss in elasticity terms ("elasticity loss") for departures from the optimal values of the two decision variables of respectively 10 percent, 20 percent, and 30 percent. The fifth line of each part of Table 2 corresponds to the Table 1 case.

The numerical results are consistent with the expected directions of comparative statics effects from explicit differentiation: as $a$ increases, both $\rho^{*}$ and $n^{*}$ increase; as $\lambda$ increases, both $\rho^{*}$ and $n^{*}$ decrease; and as $c$ increases, both $\rho^{*}$ and $n^{*}$ decrease. But the numerical results do give us some additional insights over those obtained from explicit differentiation. For example, while variations in $a$ and $c$ have relatively small effects on optimal $\rho^{*}$, variations in $\lambda$ have a relatively large effect.

Since the emphasis in this research is on the opportunity cost of sub-optimal diversification, our special interest is in the last three columns of the table, which show average loss elasticity for departures from optimal diversification of respectively 10 percent, 20 percent and 30 percent. While it is true that losses become larger as the percentage departures become larger, in no case are the losses numerically substantial. The largest loss elasticity shown in Table 2 pertains to the first line in the middle part $\mathrm{B}$ of the table, for a risk aversion parameter value of $\lambda=0.75$, the computed loss elasticity is 0.108268 . This is approximately one tenth of one percent. For the computation using larger divergences from the optimal values (40,60 and 80 percent below and above the optimum values), the highest average loss in elasticity terms was observed for 80 percent departures from the optimal levels: 0.363319 . This is well under one half of one percent.

\section{Conclusion}

The extensive theoretical literature on diversification provides an abundance of very precise necessary and sufficient conditions for the attainment of optimality. However, the practical relevance of these mathematical principles has been questioned by a wide variety of research that suggests that many if not most individual investors utilize investment strategies that are distinctly sub-optimal relative to the theoretical indications. Is this because investors are truly irrational, which is in conflict with the fundamental economic assumption of rationality? Or is it because despite the complexity of the theoretical models, they somehow fail to adequately incorporate such significant real-world complications as transactions costs, asymmetric information, different investor experiences and preferences, and so on? This research examines a third possibility: that investors do not have much incentive to pursue optimal diversification simply because the numerical payoff to the effort is minor to the point of being inconsequential. 
Utilizing the numerically implemented and empirically supported model of optimal diversification developed by Yunker and Melkumian (2010), the present research estimates the numerical opportunity costs (welfare losses) resulting from sub-optimal diversification on the part of the individual investor. The two decision variables in the model are the proportion of total portfolio value allocated to stocks $(\rho)$, and the number of stocks in the portfolio $(n)$. The criterion variable $(L)$ is based on the conventional mean-variance formulation. The investigation technique involves computation of optimal $\rho, n$ and $L$, followed by determination of numerical reductions in $L$ consequent upon departures of $\rho$ and $n$ from their optimal levels. This was done for a range of departures of $\rho$ and $n$ from their optimal levels, over a wide range of model parameter values. Losses are computed initially in absolute terms, then in percentage terms, and finally in elasticity terms (percentage reduction in $L$, divided by percentage departures in $\rho$ and $n$ from their optimal levels). The results suggest that the numerical opportunity costs from sub-optimal diversification are quite minor, even for substantial departures from the optimal levels of the decision variables, over a wide range of model parameter values.

The suggestion from the research is that individual investors tend to "satisfice" rather than "maximize" or "optimize" in making their investment decisions, including decisions respecting the nature and degree of diversification. The term "satisfice" was coined by Herbert Simon in 1956 to denote the objective of achieving a satisfactory level of welfare, as opposed to the objective of achieving the highest level of welfare. A rational decision-maker might settle for a satisfactory level of welfare if the costs of information acquisition to achieve the highest level are too high, and/or if there is a very small numerical difference between the satisfactory level of welfare and the highest level of welfare. The well-known efficient markets hypothesis implies that it does not benefit the typical individual investor very much to allocate a great deal of time and effort to selecting investments, because of the minor expected gains from such an allocation. The results obtained here are generally consistent with this implication.

\section{References}

Alessie, R., Hochguertel, S., \& van Soest, A. (2004). Ownership of stocks and mutual funds: A panel data analysis. Review of Economics and Statistics, 86(3): 783-796.

http://dx.doi.org/10.1162/0034653041811761

Barber, B., \& Odean, T. (2000). Trading is hazardous to your wealth: The common stock investment performance of individual investors. Journal of Finance, 55(2): 773-806. http://dx.doi.org/10.1111/10022-1082.00226

Basu, D., Oomen, R., \& Stremme, A. (2010). International dynamic asset allocation and return predictability. Journal of Business Finance and Accounting, 37(7-8): 1008-1025.

http://dx.doi.org/101111/j.1468-5957.2010.02195.x

Benartzi, S., \& Thaler, R. (2001). Naïve diversification strategies in defined contribution savings plans. American Economic Review, 91(1): 79-98. [Online] Available: http://www.jstor.org/stable/2677899

Bera, A., \& Park, S. (2008). Optimal portfolio diversification using the maximum entropy principle. Econometric Review, 27(4-6): 484-512. http://dx.doi.org/10.1080/07474930801960394

Blume, M., \& Friend, I. (1975) The asset structure of individual portfolios and some implications for utility functions. Journal of Finance, 30(2): 585-603. http://dx.doi.org/10.1111/j.1540-6261.1975.tb01833.x

Brainard, S. (1991) Protecting losers: Optimal diversification, insurance, and trade policy. NBER Working Paper \#3773. [Online] Available: http://www.nber.org/papers/w3773

Brennan, M. (1975). The optimal number of securities in a risky asset portfolio when there are fixed costs of transacting: Theory and some empirical results. Journal of Financial and Quantitative Analysis, 10(3): 483-496. http://dx.doi.org/10.2307/2330492

Calvet, L., Campbell, J., \& Sodini, P. (2009). Fight or flight? Portfolio rebalancing by individual investors. Quarterly Journal of Economics, 124(1): 301-348. http://dx.doi.org/10.1162/qjes.2009.124.1301

Carroll, C. (2000). Portfolios of the rich. NBER Working Paper \#7826.

[Online] Available: http://www.nber.papers/w7826

Cheng, P., \& Liang, Y. (2000). Optimal diversification: Is it really worthwhile? Journal of Real Estate Portfolio Management, 6(1): 7-16.

[Online] Available: http://ares.metapress.com/content/g6087j7621g40gh6

Cohen, R., Gompers, P., \& Vuolteenaho, T. (2002). Who under-reacts to cash-flow news? Evidence from trading between individuals and institutions. Journal of Financial Economics 66(2-3): 409-462. 
http://dx.doi/org/10.1016/S0304-405X(02)00229-5

De Wit, D. (1998). Naïve diversification. Financial Analysts Journal, 54(4): 95-100. [Online] Available: http://www.jstor/org/stable/4480096

Duchin, R., \& Levy, H. (2009). Markowitz versus the Talmudic portfolio diversification strategies. Journal of Portfolio Management, 35(2): 71-74. http://dx.doi/org/10.3905/JPM.2009.35.2.071

Dynkin, L., Hyman, J., \& Konstantinovsky, V. (2002). Sufficient diversification in credit portfolios: Number of issues and downgrade risk. Journal of Portfolio Management, 29(1): 89-114.

http://dx.doi/org/10.3905/jpm.2002.319867

Elton, E., Gruber, M., \& Busse, J. (2004). Are investors rational? Choices among index funds. Journal of Finance, 59(1): 261-287. http://dx.doi/org/10-1111/j.1540-6261.2004.00633.x

Ferris, S., Haugen, R., \& Makhija, A. (1988). Prediction of contemporary volume with historic volume at differential price levels: Evidence supporting the disposition effect. Journal of Finance, 43(3): 677-697. [Online] Available: http://www.jstor.org/stable/2328191

Frederik, L. (2006). The effect of information quality on optimal portfolio choice. Financial Review, 42: 157-185. http://dx.doi/org/10.1111/j.1540-6288.2006.00137.x

Ghosh, D. (2010). Asset acquisition, diversification, and revision: Theoretic exercises in portfolio theory. Quarterly Journal of Finance and Accounting, 49(1): 19-38. Retrieved 5/7/2012 from the EconLit database.

Giliberto, M., Hamelink, F., Hoesli, M., \& MacGregor, B. (1999). Optimal diversification within mixed-asset portfolios using a conditional heteroskedasticity approach: Evidence from the U.S. and the U.K. Journal of Real Estate Portfolio Management, 5(1): 31-45.

[Online] Available: http://ares.metapress.com/content/121545/

Goetzmann, W., \& Kumar, A. (2008). Equity portfolio diversification. Review of Finance, 12: 433-463. http://dx.doi/org/10.1093.rof/rfn005

Goldman, M. (1979). Anti-diversification or optimal programmes for infrequently revised portfolios. Journal of Finance, 34(2): 505-516. [Online] Available: http://www.jstor.org/stable/2326993

Gomes, J., \& Livdan, D. (2004). Optimal diversification: Reconciling theory and evidence. Journal of Finance, 59(2): 507-535. http://dx.doi/org/10.1011/j.1540-6261.2004.00641.x

Green, R., \& Rydqvist, K. (1997). The valuation of nonsystematic risk and the pricing of Swedish lottery bonds. Review of Financial Studies, 10(2): 447-480. http://dx.doi/org/10.1093/rfs/10.2.447

Grinblatt, M., \& Keloharju, M. (2001). What makes investors trade? Journal of Finance, 56(2): 589-616. http://dx.doi/org/10.1111/0022-1082.00338

Guiso, L., \& Paiella, M. (2008). Risk aversion, wealth and background risk. Journal of the European Economic Association, 6(6): 1109-1150. http://dx.doi/org/10.1162/JEEA.2008.6.6.1109

Hirshleifer, D., \& Luo, G. (2001). On the survival of overconfident traders in a competitive security market. Journal of Financial Markets, 4(1): 73-84. http://dx.doi/org/10.1016/S1386-4181(00)00014-8

Huberman, G. (2001). Familiarity breeds investment. Review of Financial Studies, 14(3): 659-680. http://dx.doi/org/10.1093/rfs/14.3.659

Kaustia, M., \& Knupfer, S. (2008). Do investors overweight personal experience? Evidence from IPO subscriptions. Journal of Finance, 63(6): 2679-2702. http://dx.doi/org/10.1111/j.1540-6261.2008.01411.x

Kelly, M. (1995). "All their eggs in one basket: Portfolio diversification of U.S. households. Journal of Economic Behavior and Organization, 27(1): 87-96. http://dx.doi.org/10.1016/0167-2681(95)00006-E

King, M., \& Leape, J. (1998). Wealth and portfolio composition: Theory and evidence. Journal of Public Economics, 69(2): 155-193. http://dx.doi.org/10.1016/S0047-2727(98)00027-9

Kocherlakota, N. (1996). Implications of efficient risk sharing without commitment. Review of Economic Studies, 63(4): 595-609. http://dx.doi/org/10.2307/2297795

Mainik, G., \& Ruschendorf, L. (2010). On optimal portfolio diversification with respect to extreme risks. Finance and Stochastics, 14: 593-623. http://dx.doi.org/10.1007/s00780-010-0122-2

Markowitz, H. (1952). Portfolio selection. Journal of Finance, 7(1): 77-91. [Online] Available: 
http://www.jstor.org/stable/2975974

Markowitz, H. (1959). Portfolio selection: Efficient diversification of investments. New York: John Wiley and Sons. McClatchey, C., \& Vandenhul, S. (2005). The efficacy of optimization modeling as a retirement strategy in the presence of estimation error. Financial Services Review, 14(4): 269-284. Retrieved 5/7/2012 from Google Scholar.

Melkumian, A. A., and Melkumian, A. V. (2009). Is more always better? Empirical evidence on optimal portfolio size. Eastern Economic Journal, 35(1): 84-95. http://dx.doi.org/10.1057/palgrave.eej.9059945

Mitton, T., and Vorkink, K. (2007). Equilibrium under-diversification and the preference for skewness. Review of Financial Studies, 20(4): 1255-1288. http://dx.doi.org/10.1093/revfin/hhm011

Morgan, K. (1995). All their eggs in one basket: Portfolio diversification of U.S. households. Journal of Economic Behavior and Organization, 27(1): 87-96. http://dx.doi.org/10.1016/0167-2681(95)00006-E

Odean, T. (1998). Are investors reluctant to realize their losses? Journal of Finance, 53(5): 1775-1798. http://dx.doi.org/10.1111/0022-1082.00072

Phillips, P., Cathcart, A., \& Teale, J. (2007). The diversification and performance of self-managed superannuation funds. Australian Economic Review, 40(4): 339-352. http://dx.doi.org/10.1111/j.1467-8462.2007.00475.x

Polbennikov, S., Desclee, A., \& Hyman, J. (2010). Horizon diversification: Reducing risk in a portfolio of active strategies. Journal of Portfolio Management, 36(2): 26-38. http://dx.doi.org/10.3905/JPM.2010.36.2.026

Polkovnichenko, V. (2005). Household portfolio diversification: A case for rank-dependent preferences. Review of Financial Studies, 18(4): 1467-1502. http://dx.doi.org/10.1093/rfs/hhi033

Poterba, J., \& Samwick, A. (2003). Taxation and household portfolio composition: U.S. evidence from the 1980s and 1990s. Journal of Public Economics, 87(1): 5-38.

http://dx.doi.org/10.1016/S0047-2727(01)00168-2

Samuelson, P. (1967). General proof that diversification pays. Journal of Financial and Quantitative Analysis, 2(1): 1-13. http://dx.doi.org/10.2307/2329779

Simon, H. (1956). Rational choice and the structure of the environment. Psychological Review, 63(2): 129-138. http://dx.doi.org/10.1037/h0042769

Stevenson, S. (2001). Bayes-Stein estimators and international real estate asset allocation. Journal of Real Estate Research, 21(1-2): 89-103. Retrieved 5/7/2012 from Google Scholar.

Vissing-Jorgensen, A., \& Attanasio, O. (2003). Stock-market participation, intertemporal substitution, and risk-aversion. American Economic Review, 93(2): 383-391.

[Online] Available: http://www.jstor.org/stable/3132259

Windcliff, H., and Boyle, P. (2004). The 1/n pension investment puzzle. North American Actuarial Journal, 8(3): 32-45. Retrieved 5/7/2012 from Google Scholar.

Yunker, J., \& Melkumian, A. (2010). The effect of capital wealth on optimal diversification: Evidence from the Survey of Consumer Finances. Quarterly Review of Economics and Finance, 50(1): 90-98. http://dx.doi.org/10.1016/j.qref.2009.09.004 
Table 1. Estimated Opportunity Costs of Sub-Optimal Diversification

A. Absolute values of criterion variable $L$ for combinations of decision variables and $n$

\begin{tabular}{l|lllllll}
$. n:$ & 26.06 & 29.78 & 33.50 & 37.22 & 40.95 & 44.67 & 48.39 \\
\hline 0.5314 & 0.053113 & 0.053103 & 0.053079 & 0.053043 & 0.053000 & 0.052952 & 0.052899 \\
0.6074 & 0.053822 & 0.053834 & 0.053825 & 0.053803 & 0.053770 & 0.053730 & 0.053685 \\
0.6833 & 0.054222 & 0.054256 & 0.054266 & 0.054258 & 0.054238 & 0.054208 & 0.054171 \\
0.7592 & 0.054310 & 0.054371 & 0.054401 & 0.054410 & 0.054403 & 0.054384 & 0.054356 \\
0.8351 & 0.054089 & 0.054179 & 0.054231 & 0.054258 & 0.054266 & 0.054259 & 0.054242 \\
0.9110 & 0.053557 & 0.053679 & 0.053756 & 0.053803 & 0.053826 & 0.053834 & 0.053828 \\
0.9870 & 0.052715 & 0.052871 & 0.052975 & 0.053043 & 0.053085 & 0.053107 & 0.053113
\end{tabular}

B. Percent loss in criterion variable $L$ for combinations of decision variables and $n$

\begin{tabular}{l|lllllll}
$. n:$ & 26.06 & 29.78 & 33.50 & 37.22 & 40.95 & 44.67 & 48.39 \\
\hline 0.5314 & 2.383559 & 2.401346 & 2.446802 & 2.511627 & 2.590538 & 2.680013 & 2.777615 \\
0.6074 & 1.079688 & 1.059359 & 1.075170 & 1.116279 & 1.175785 & 1.249090 & 1.333010 \\
0.6833 & 0.346153 & 0.282627 & 0.264840 & 0.279070 & 0.316585 & 0.371563 & 0.439976 \\
0.7592 & 0.182955 & 0.071149 & 0.015811 & 0.000000 & 0.012936 & 0.047433 & 0.098514 \\
0.8351 & 0.590093 & 0.424925 & 0.328083 & 0.279070 & 0.264840 & 0.276698 & 0.308624 \\
0.9110 & 1.567567 & 1.343956 & 1.201658 & 1.116279 & 1.072296 & 1.059359 & 1.070305 \\
0.9870 & 3.115378 & 2.828240 & 2.636533 & 2.511627 & 2.435303 & 2.395417 & 2.383559
\end{tabular}

C. Loss in elasticity terms in criterion variable $L$ for combinations of decision variables and $n$

\begin{tabular}{|c|c|c|c|c|c|c|c|}
\hline$n:$ & 26.06 & 29.78 & 33.50 & 37.22 & 40.95 & 44.67 & 48.39 \\
\hline 0.5314 & 0.079452 & & & & & $\longrightarrow$ & 0.092587 \\
\hline 0.6074 & \multirow[t]{5}{*}{4} & 0.052968 & 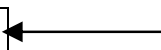 & & & 0.062455 & \multirow{5}{*}{$\downarrow$} \\
\hline 0.6833 & & $T$ & 0.026484 & 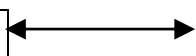 & 0.031658 & $T$ & \\
\hline 0.7592 & & & $\boldsymbol{A}$ & 0.000000 & $\vec{A}$ & & \\
\hline 0.8351 & & $\downarrow$ & 0.032808 & $\longrightarrow$ & 0.026484 & $\downarrow$ & \\
\hline 0.9110 & & 0.067198 & $\leftarrow$ & & & 0.052968 & \\
\hline 0.9870 & 0.103846 & & & & & & 0.079452 \\
\hline
\end{tabular}

Notes:

Parameter values: $\overline{r_{s}}=0.08 ; \quad r_{b}=0.04 ; \quad \sigma_{m}^{L}=0.025 ; \quad \sigma_{s}^{L}=0.050 ; \quad=1 ; c=5 ; a=250000$

Computation of average loss in elasticity terms in criterion variable $L$ :

--for 10 percent above and below optimal and $n$ values:

$0.029359=(0.026484+0.031658+0.026484+0.032808) / 4$

--for 20 percent above and below optimal and $n$ values:

$0.058897=(0.052968+0.062455+0.052968+0.067198) / 4$

--for 30 percent above and below optimal and $n$ values:

$0.088834=(0.079452+0.092587+0.079452+0.103846) / 4$ 
Table 2. Selected Comparative Statics Results

A. Capital Wealth Parameter $(a)$

Loss elasticity for departure $\%=$

\begin{tabular}{l|cccccc}
$a$ & $*$ & $n^{*}$ & $L^{*}$ & $10 \%$ & $20 \%$ & $30 \%$ \\
\hline 25,000 & 0.6710 & 10.40 & 0.051256 & 0.030489 & 0.061512 & 0.093718 \\
75,000 & 0.7255 & 19.48 & 0.053160 & 0.029889 & 0.060098 & 0.091019 \\
100,000 & 0.7355 & 22.81 & 0.053524 & 0.029744 & 0.059767 & 0.090411 \\
150,000 & 0.7473 & 28.38 & 0.053963 & 0.029558 & 0.059347 & 0.089647 \\
200,000 & 0.7544 & 33.08 & 0.054228 & 0.029441 & 0.059083 & 0.089169 \\
250,000 & 0.7592 & 37.22 & 0.054410 & 0.029359 & 0.058897 & 0.088834 \\
$1,000,000$ & 0.7796 & 76.45 & 0.055195 & 0.028984 & 0.058059 & 0.087336 \\
$2,500,000$ & 0.7871 & 122.03 & 0.055488 & 0.028837 & 0.057731 & 0.086754 \\
$5,000,000$ & 0.7909 & 173.41 & 0.055637 & 0.028761 & 0.057562 & 0.086454 \\
$10,000,000$ & 0.7936 & 246.07 & 0.055743 & 0.028706 & 0.057441 & 0.086240 \\
$50,000,000$ & 0.7971 & 552.70 & 0.055885 & 0.028632 & 0.057277 & 0.085951
\end{tabular}

B. Risk Aversion Parameter ( )

Loss elasticity for departure $\%=$

\begin{tabular}{l|cccccc} 
& $*$ & $n^{*}$ & $L^{*}$ & $10 \%$ & $20 \%$ & $30 \%$ \\
\cline { 5 - 7 } 0.75 & 1.0196 & 43.29 & 0.059491 & 0.035821 & 0.071832 & 0.108268 \\
0.80 & 0.9544 & 41.85 & 0.058217 & 0.034313 & 0.068814 & 0.103735 \\
0.85 & 0.8969 & 40.54 & 0.057095 & 0.032926 & 0.066038 & 0.099564 \\
0.90 & 0.8459 & 39.34 & 0.056099 & 0.031645 & 0.063474 & 0.095712 \\
0.95 & 0.8003 & 38.24 & 0.055210 & 0.030459 & 0.061101 & 0.092146 \\
1.00 & 0.7592 & 37.22 & 0.054410 & 0.029359 & 0.058897 & 0.088834 \\
1.25 & 0.6035 & 33.08 & 0.051382 & 0.024857 & 0.049884 & 0.075286 \\
1.50 & 0.5000 & 30.03 & 0.049376 & 0.021544 & 0.043248 & 0.065307 \\
2.00 & 0.3712 & 25.74 & 0.046888 & 0.016996 & 0.034137 & 0.051597 \\
2.50 & 0.2942 & 22.81 & 0.045410 & 0.014023 & 0.028179 & 0.042627 \\
3.50 & 0.2068 & 18.97 & 0.043741 & 0.010374 & 0.020862 & 0.031603
\end{tabular}

C. Transactions cost parameter (c)

Loss elasticity for departure $\%=$

\begin{tabular}{l|cccccc}
$c$ & $*$ & $n^{*}$ & $L^{*}$ & $10 \%$ & $20 \%$ & $30 \%$ \\
\hline 2.50 & 0.7712 & 53.47 & 0.054867 & 0.029144 & 0.058416 & 0.087972 \\
3.00 & 0.7684 & 48.64 & 0.054761 & 0.029195 & 0.058529 & 0.088175 \\
3.50 & 0.7659 & 44.88 & 0.054664 & 0.029241 & 0.058632 & 0.088359 \\
4.00 & 0.7635 & 41.85 & 0.054574 & 0.029283 & 0.058727 & 0.088529 \\
4.50 & 0.7613 & 39.34 & 0.054489 & 0.029322 & 0.058815 & 0.088686 \\
5.00 & 0.7592 & 37.22 & 0.054410 & 0.029359 & 0.058897 & 0.088834 \\
5.50 & 0.7572 & 35.40 & 0.054334 & 0.029393 & 0.058975 & 0.088974 \\
6.00 & 0.7553 & 33.81 & 0.054262 & 0.029426 & 0.059048 & 0.089106 \\
6.50 & 0.7535 & 32.40 & 0.054194 & 0.029457 & 0.059117 & 0.089231 \\
7.00 & 0.7517 & 31.15 & 0.054128 & 0.029486 & 0.059184 & 0.089351 \\
7.50 & 0.7500 & 30.03 & 0.054064 & 0.029514 & 0.059247 & 0.089466
\end{tabular}




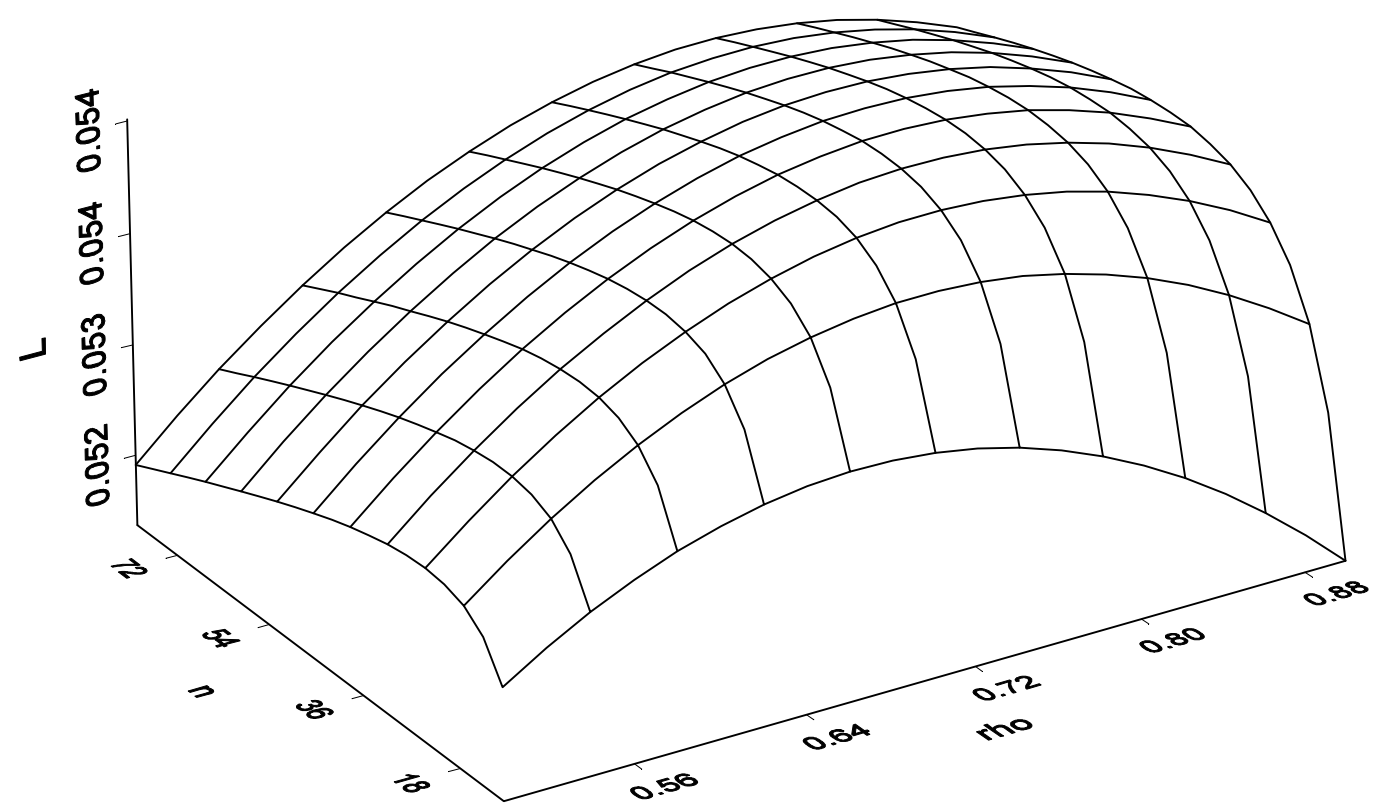

Figure 1.3D Surface Graph of the Effect of Optimal Proportion ( $\rho=$ "rho") and Number $(n)$ on Criterion Variable $L$ 